\title{
A Theoretical Integration of Schema Therapy and Cognitive Therapy in OCD Treatment: Experiential Techniques and Cognitive-Based Interventions in Action (Part III)
}

\author{
Barbara Basile $^{1 *}$, Olga Ines Luppino1, Francesco Mancini' ${ }^{1,2}$, Katia Tenore ${ }^{1}$ \\ ${ }^{1}$ Association of Cognitive Psychology, School of Cognitive Psychotherapy, Rome, Italy \\ ${ }^{2}$ Marconi University, Rome, Italy \\ Email: ^basile_barbara@yahoo.it, *basile@apc.it
}

How to cite this paper: Basile, B., Luppino, O. I., Mancini, F., \& Tenore, K. (2018). A Theoretical Integration of Schema Therapy and Cognitive Therapy in OCD Treatment: Experiential Techniques and Cognitive-Based Interventions in Action (Part III). Psychology, 9, 2296-2311.

https://doi.org/10.4236/psych.2018.99131

Received: July 2, 2018

Accepted: September 8, 2018

Published: September 11, 2018

Copyright $\odot 2018$ by authors and Scientific Research Publishing Inc. This work is licensed under the Creative Commons Attribution International License (CC BY 4.0).

http://creativecommons.org/licenses/by/4.0/

\begin{abstract}
This final article is part of the trilogy presenting a possible integration of Schema Therapy (ST) and Cognitive Therapy (CT) in Obsessive-compulsive disorder (OCD) treatment. It aims at describing how experiential and cognitive based acceptance techniques might be applied to treat this psychopathological condition. In the first article published in this special issue (Luppino et al., 2018) we reported the main data supporting the role of proximal psychological determinants in the genesis and maintenance of the obsessive symptomatology, highlighting the role of deontological guilt and disgust, and of the Not Just Right Experience. According to these, we described the internal profile of the disorder as conceptualized by Mancini's (2018) cognitive model. In the second manuscript (Tenore et al., 2018) we proposed a conceptualization of OCD, in terms of schemas and modes (as proposed by ST), integrating it with the previously described cognitive model. In agreement with these two articles, the aim of this work is to explain how experiential and cognitive techniques can be integrated to explain obsessive functioning and to achieve a successful treatment. We first describe emotion focused-experiential procedures derived from the ST framework, specifically focusing on imagery techniques, such as diagnostic imagery, rescripting and Healthy Adult imagery. Secondly we explain how chairwork can be applied to change obsessive dysfunctional schema modes. Finally, we focus on cognitive based acceptance intervention aimed at reducing the typical feelings of deontological guilt and disgust, two core emotions in OCD. In the conclusion we briefly resume the major aspects proposed in the three articles, and we present some potential further applications of a joined approach applied to other psychopathological
\end{abstract}


conditions.

\section{Keywords}

Obsessive-Compulsive Disorder, Schema Therapy, Cognitive Therapy, Imagery with Rescripting, Chairwork, Acceptance

\section{Introduction}

In this last paper of the trilogy published in this number of Psychology we propose an integrated model where cognitive (CT) and schema therapy (ST) elements and techniques are combined in order to facilitate a deeper understanding of OCD functioning and treatment intervention. In line with the two previous articles (see Luppino et al., 2018; and Tenore et al., 2018, in this issue), our aim here is to explain how schema and cognitive strategies and techniques can be applied to treat obsessive symptoms. Emotion-focused experiential techniques might be particularly useful to explore and to manage early-life factors that might have sensitized patients towards actual obsessive pathology, while cognitive techniques might be applied to understand and treat actual OCD symptoms. In this view, the ST framework might be particularly useful in the sense of giving a richer representation of the OCD mental state, in terms of early maladaptive schemas (Young et al., 2003), and of the early negative experiences that might have contributed to the development of such schemas, setting the basis for future symptomatic development. As well, schema modes conceptualization might be helpful in illustrating the obsessive functioning in a more dynamic way, with a dedicated focus on the patient's actual emotional state. On the other hand, the cognitive model is particularly useful (Luppino et al., 2018) to understand beliefs, goals, maintenance factors, and the general mind set, of obsessive patients.

Accordingly the aim of this article is to explain how experiential and cognitive techniques can be combined and applied in the treatment of obsessive symptomatology. In the first part we will focus on emotion-focused experiential techniques, explaining some possible applications of imagery work and chair dialogues. Experiential techniques are used to promote change, emotional growth and personal empowerment, helping the patient to get in touch with negative emotions and distressing early memories and to change its associated maladaptive schemas and behaviors. In the second part of the manuscript we will address how cognitive strategies can be applied to decrease guilt and disgust, two core feelings within the obsessive symptomatology (Mancini, 2018; Salkovsis, 1999; Berle \& Phillips, 2006). Both kinds of intervention will be further deepened reporting some clinical examples from Mark's case, which has been described in Luppino et al. (2018). In the last part of the paper we will discuss some overall conclusions, addressing some possible future directions for a further integration of CT and ST in other psychopathological conditions. 


\section{Experiential Techniques}

\subsection{Imagery Work}

Imagery is a nonverbal strategy for producing change (Smucker, Dancu, Foa, \& Niederee, 1995; Arntz \& Weertman, 1999). It makes it possible to recall early negative emotional events, which are mainly stored in the form of images (Conway \& Pleydell-Pearce, 2000). Particularly, Imagery with Rescripting (ImRS) is a technique which aims to modify the meanings associated with negative or traumatic memories (Arntz \& Weertman, 1999; Smucker, Dancu, Foa, \& Niederee, 1995), connecting the patient's primary emotions to early maladaptive schemas. Imagery applies to core beliefs as well as to other cognitive behavioral constructs, and it has been recognized to have greater power than verbal representation (Paivio, Smythe, \& Yuille, 1968). Imagery can be applied when sufficient safety and trust in the therapist has been established.

Other kinds of imagery exercises can be used in different phases of therapy, in order to prepare the patient for future ImRS intervention, or to strengthen the Healthy Adult mode. These include imagery associated with a safe place and diagnostic imagery (Arntz, 2011; Young et al., 2003). They can be applied during the first stages of therapy. In later stages Healthy Adult imagery can be utilized. Here, we will briefly describe the rationale for each imagery technique, and we invite you to examine Table 1 for a detailed description concerning the procedure for each exercise. After each imagery session, specifically after having employed ImRS, clients are asked how vivid the image was, what they have noticed about the experience, and whether they recognize a relationship between their actual problems and what has happened in the past. They are also asked whether they have developed a new meaning (of themselves or others involved in the episode) in relation to what happened in the image. This final phase provides the most individualized formulation of the activated schema, associated with the patient's personal life history. Each imagery exercise must be audio-recorded and is given to the client after the session to listen to as homework.

1) Safe place imagery

In this imagery exercise, the patient and therapist work together to create an image of a place where the patient feels safe. This image can be real (i.e., a place from the past, an actual one, or even the therapist's room) or made-up (i.e., a safety bubble, Farrell \& Shaw, 2018), and it can be used later to bring safety into the session whenever needed, as for instance after an imagery with rescripting exercise (Arntz, 2011; Young et al., 2003). Safe places might also include other people or animals, or no one; the essential aspect is that the client should feel completely safe.

\section{2) Diagnostic imagery}

In diagnostic imagery the patient is asked to share with the therapist an emotionally loaded memory or image of him/herself as a child with each of his/her parents (or other caregivers). The images often include major events that have 
Table 1. Principal goals and phases of therapy in which of each imagery exercise can be used, and detailed clinical procedures are reported.

\begin{tabular}{|c|c|c|c|}
\hline $\begin{array}{c}\text { Type of imagery } \\
\text { exercise }\end{array}$ & Goal & When to use it & Procedure \\
\hline Safe place & $\begin{array}{l}\text { Allow the patient to create } \\
\text { an image in which he/she } \\
\text { feels safe and protected }\end{array}$ & $\begin{array}{l}\text { At the beginning of } \\
\text { therapy, when a trustable } \\
\text { therapeutic alliance has } \\
\text { been created. } \\
\text { At the end of ImRS } \\
\text { exercises or to heal } \\
\text { intense negative } \\
\text { emotions that arose } \\
\text { within the therapy } \\
\text { session. }\end{array}$ & $\begin{array}{l}\text { 1) The therapist asks the patient to sit in a comfortable position and } \\
\text { to close his/her eyes. } \\
\text { 2) The therapist asks the patient to recall a real or invented place } \\
\text { where he/she feels secure and safe. } \\
\text { 3) Once the place has been identified, the therapist asks questions } \\
\text { about sights, sounds, smells, behaviors, bodily sensations, } \\
\text { emotions, and thoughts the patient is feeling. } \\
\text { 4) The client lingers for few minutes in his/her safe place, before } \\
\text { ending the exercise. } \\
\text { 5) Debriefing phase. }\end{array}$ \\
\hline Diagnostic & $\begin{array}{l}\text { Helps the patient to } \\
\text { understand the connection } \\
\text { between early negative } \\
\text { memories and current } \\
\text { problems and how } \\
\text { they have influenced the } \\
\text { development of early } \\
\text { maladaptive schemas }\end{array}$ & $\begin{array}{l}\text { At the beginning of } \\
\text { therapy, when a } \\
\text { trustable therapeutic } \\
\text { alliance has been } \\
\text { created. }\end{array}$ & $\begin{array}{l}\text { 1) The therapist asks the patient to sit in a comfortable position and } \\
\text { to close his/her eyes. } \\
\text { 2) The therapist asks the patient to recall a strong negative event of } \\
\text { the past or from a recent situation. } \\
\text { 3) Once the episode has been identified, the therapist asks questions } \\
\text { to get a detailed description of what is happening and on patient's } \\
\text { bodily sensations, emotions, thoughts and behaviors. } \\
\text { 4) Once a negative feeling arises, the therapist might conclude the } \\
\text { imagery or guide the client to go to his/her safe place. } \\
\text { 5) Debriefing and discussion on the exercise. }\end{array}$ \\
\hline ImRS & $\begin{array}{l}\text { Allows to get in touch with } \\
\text { intense negative emotions } \\
\text { associated with childhood } \\
\text { experiences and to identify } \\
\text { their associated unmet core } \\
\text { needs. } \\
\text { Allows healing and fulfilling } \\
\text { those needs and bad feelings. } \\
\text { Helps to understand the link } \\
\text { between the past and current } \\
\text { problems. } \\
\text { Changes the meaning of } \\
\text { what has happened } \\
\text { intervening on patient's core } \\
\text { beliefs. }\end{array}$ & $\begin{array}{l}\text { Across the whole } \\
\text { change phase of therapy } \\
\text { and in the final part of } \\
\text { therapy, to further } \\
\text { strengthen the Healthy } \\
\text { Adult mode of the } \\
\text { patient. }\end{array}$ & $\begin{array}{l}\text { 1) The therapist asks the patient to sit in a comfortable position and } \\
\text { to close his/her eyes. } \\
\text { 2) The client describes a recent episode where has experienced an } \\
\text { intense negative emotion. Therapist asks a detailed description } \\
\text { about the episode. } \\
\text { 3) Using the floating back technique to connect the activated } \\
\text { emotion with an episode from the past where a similar feeling was } \\
\text { present. Therapist asks a detailed description of the episode, } \\
\text { focusing on the child's emotions and unmet core needs. } \\
\text { 4) The patient's Healthy Adult mode (or the therapist or any other } \\
\text { real or fantasized helping figure) intervenes and fulfills child's } \\
\text { needs (rescripting). } \\
\text { 5) The child describes from his/her perspective the adult } \\
\text { intervention (interaction between the child and the adult goes on } \\
\text { until all unmet needs within the episode are satisfied). } \\
\text { 6) The Healthy Adult mode (or any other helping figure) goes to the } \\
\text { recent episode and helps the patient to deal with the difficult situation. } \\
\text { 7) After client's opens his/her eyes, debriefing and discussion on } \\
\text { what has happened in the exercise might take place. }\end{array}$ \\
\hline Healthy Adult & $\begin{array}{l}\text { Strengthen the Healthy } \\
\text { Adult mode of the client }\end{array}$ & $\begin{array}{l}\text { In the final phase of } \\
\text { treatment. }\end{array}$ & $\begin{array}{l}\text { 1) The therapist asks the patient to sit in a comfortable position and } \\
\text { to close his/her eyes. } \\
\text { 2) The client describes a recent episode where he/she was in the } \\
\text { Healthy Adult mode. Therapist asks a detailed description about } \\
\text { the episode, specifically focusing on posture, tone of voice and } \\
\text { other bodily sensations, emotions and thoughts. } \\
\text { 3) The client is asked to hold back and breath through this healthy } \\
\text { mode and to imagine a future near difficult moment where } \\
\text { his/her Healthy Adult helps to cope with the event. }\end{array}$ \\
\hline
\end{tabular}


influenced the development of the client's maladaptive schemas (Arntz, 2011; Young et al., 2003). After the exercise, the therapist helps the patient understand the connection between the past episode and his/her current problems. The major aim of diagnostic imagery is to get some initial information about the type of early experiences and relationships that are likely to have played a role in the development of maladaptive schemas', as these might be related to the patient's actual problems. For example, Mark might have recollected a specific memory where he was 6 years old and was with his mother, who, very angry at him, was wearing a scornful expression on her face because he had lost his school bag. As a child, Mark was very upset, and continued to feel very guilty about what had happened. To restore Mark's negative emotions within the context of the diagnostic imagery exercise, the therapist might ask him to go back to his safe place, and to linger within the feelings of security and care generated by that place.

3) Imagery with Rescripting (ImRS)

Imagery with rescripting technique was first developed by Smucker and his colleagues in 1995 and applied to women diagnosed with a post-traumatic stress disorder. Afterwards, it was fluidly integrated within the ST model as one of its major emotion-focused experiential techniques.

The major goals of ImRS are (Smucker et al., 1995; Arntz \& Weertman, 1999; van Vreeswijk et al., 2012):

1) To obtain a better understanding of the childhood origin of maladaptive schemas.

2) To link the origins of the client's schemas in childhood and adolescence together with his/her current problems.

3) To identify more precisely schemas that are central to the patient by eliciting core images linked to primary emotions like fear, loneliness, hopelessness, shame, guilt, grief and so on. In the case of OCD, the most relevant emotions are usually guilt (Basile et al., 2018; Veale et al., 2012), often associated with parental reproach/blame experiences (Basile et al., 2018), and fear of being disgusting (Tenore et al., 2018; Mancini, 2018).

4) To help the patient feel and accept the emotions associated with those images more fully (see also the acceptance intervention paragraph, in the second part of the article).

5) To change the meaning of negative memories and to allow cognitive restructuring, modifying patient's core beliefs and self-representation (Arntz, 2011; Brewin, 2006; Mancini \& Mancini, 2018).

6) To provide a basis for self-compassion by experiencing the emotional pain of the image.

7) And, for the therapist, to better understand the patient in an emotional sense, facilitating empathic responsiveness and an overall therapeutic alliance.

In the context of OCD, past episodes involving patients feeling guilty or disgusting are quite frequent (Luppino et al., 2018; Mancini, 2018; Berle \& Phillips, 2006; Sprengelmeyer et al., 1997; Basile et al., 2018) and are often associated with the client's actual symptoms. In an imagery with rescripting exercise, for exam- 
ple, Mark reported a specific negative episode that took place in his childhood. The client's memory developed from a recent negative event in which Mark had experienced a great deal of stress when he thought he had lost his wallet on the bus. In the childhood memory, both of Mark's parents had become very irritated and upset when Mark had received a bad mark in a school test. Within the rescripting phase, both the therapist and Mark as an adult entered the scene by comforting and supporting little Mark, who was feeling deeply sad and guilty for having disappointed his parents' expectations, fearing they would reject him, or even leave him. The adult Mark hugged the child, promising he was never going to leave him and that he would always love him, no matter what he could do wrong! In a second intervention, in the context of the same episode, the therapist spoke to Mark's parents, while the little Mark and adult Mark listened, explaining how exaggerated their reaction had been, and how this was affecting their son's psychological wellbeing. The therapist explained that everyone, especially children, has the right to make mistakes, and how it is through errors that children can learn, understand how to cope with their problems and develop a healthy sense of self-esteem. She then asked them to lower their unrelenting standards towards the boy, who was then just an 8 years old child, with specific needs for care, acceptance, encouragement, support and reassurance that needed to be satisfied. After the imagery session, Mark recognized that maybe his long-lasting self-beliefs about being "a bad and difficult child", with exaggerated needs and requests towards his caregivers, were incorrect. In addition, the client recognized that maybe his parents were too demanding and only minimally tuned into their son's own feelings and emotional needs. Although this different awareness and perspective was painful, it allowed Mark to gain a new perception of himself and improve his sense of self-worth.

4) Healthy Adult Imagery

In the later phase of therapy, the Healthy Adult mode of the client becomes more integrated and mature (see also the cognitive interventions section). This mode includes the capacity for reality-oriented reappraisal of thoughts and attitudes. The patient is able to behave in a rational and reflective way, promoting mature judgment, being mindful and accepting, tuned in with the emotions of the Vulnerable child, and nurturing his/her needs. Imagery exercises can allow the client to get in contact with his/her healthy mode, and the thoughts, feelings and bodily sensations associated with that mode, and to use these sensations to cope with future difficult circumstances. In Mark's case, in the final stage of therapy, several exercises with the Healthy Adult were implemented with respect to threatening situations such as going to play soccer, looking at other men and tolerating thoughts which emerged about how they looked, checking the gas was switched off or the door was locked. In one of those exercises, Mark recollected a recent event in which he had coped in a healthy and functional way with an unpleasant situation. Thanks to the image (and its associated bodily feelings and mindset) of himself as a Healthy Adult, for whom making mistakes was acceptable and bearable, not necessarily leading to punishment or abandonment, Mark 
was able to imagine himself dealing with an upcoming stressful situation. When, the following week, a stressful episode did occur, the client, in his Healthy Adult mode, was more able to cope in it a healthy and functional way.

\subsection{Evidences about ImRS Efficacy}

Evidence about the efficacy of ImRS in OCD (Veale et al., 2012; Tenore, Basile, Cosentino et al., 2018; Fink et al., 2018) and in other disorders (see Arntz, 2012 and Morina et al., 2017, for a review) has been collected in the last decade. Imagery exercises have been found to reduce the valence of the associated memory (Dibbets, Poort, \& Arntz, 2012) and the strength of the encapsulated negative beliefs (Lee \& Kwon, 2013; Wild et al., 2007, 2008). The latter is particularly relevant in depressive symptoms (Renner et al., 2018), eating disorders (Cooper, Todd, \& Turner, 2007; Cooper, 2012) and OCD (Veale et al., 2012; Basile et al., 2018).

\section{Chair Modes Work}

Chairwork derived from Gestalt therapy. This technique was created by Moreno in the psychodrama context $(1989 ; 2012)$, and was further developed and applied within psychotherapeutic settings by Perls (1973) and Kellogg (2004). Traditionally, chairwork involves one single chair (the "empty chair") which is used representing a significant person in the client's (actual or past) life. It is a particularly creative and flexible technique that can be used in many situations, using internal (i.e., modes work, making choices) and external (i.e., loss, grief) dialogues (Kellogg, 2004). Within the ST model this technique has been particularly rewarding in helping the therapist to identify and deal with the client's modes. In line with the ST purpose, and according to its case formulation, more chairs are introduced, with every chair representing a different mode for the patient (Kellogg, 2004). In fact, although chair dialogues are usually conducted between two sides of the patient, it is also possible that more than two modes are involved (multiple chair dialogue). During chair dialogues, the patient is helped to set boundaries for his/her punishing and demanding sides, while at the same time he/she is trained to further develop and strengthen his/her healthy side (Healthy Adult mode), able to take care of the inner Vulnerable child side (Vulnerable Child mode). The therapist guides the patient's different modes through the dialogues.

Chairwork is particularly useful in OCD treatment where several dysfunctional parental and coping modes interfere with the nurture of the Vulnerable Child mode, and with the strengthening of the Healthy Adult mode. Additionally, dysfunctional modes might per se trigger obsessive thoughts, fostering negative feelings such as guilt and disgust towards others or the self, or promoting avoidance and compulsive behaviors. Chairwork is used in parallel with imagery work and in its first application is aimed at identifying and labeling the different modes. In the first stage of Mark's therapy, chairwork made it possible to identi- 
fy his various modes (i.e., overcontroller/perfectionstic, detached Protector and self-soother, Demanding and Punitive Parental modes), and to define their specific function in Mark's life. This was done using a "Mode Interview". When interviewing the mode, the client is asked to move to a new chair, to play that mode and let the therapist explore it. For instance, the therapist asked Mark to put his Detached Protector part (which avoided any contact with negative emotions and needs associated with his Vulnerable Child mode) on a new chair, and she interviewed it directly asking questions such as: "When did you develop in Mark's life? Why did you develop as a mode in the first place? What are your specific functions in Mark's life? What are your pros and cons? Can we give you a name that allows us to characterize you?" In this exploring phase, the aim of the therapist is to better understand the mode, to support and validate its adaptive function in the client's early life, and to help the patient to recognize it as a "part" of him/herself, allowing some distancing (so called, "disidentification process", Roediger, 2012). At the same time, exploring its cons might allow the patient to acknowledge its costs in his/her life, motivating some new more functional behaviors. Another important aspect of the mode interview is its association with specific parental voices. When the therapist interviewed Mark's Demanding/Punitive Parent mode, for example, its association with his maternal messages emerged quite clearly, also throwing light on some of the ways in which the client had, as a Child, developed his over-controller and perfectionistic behavior in order to compensate for his fear of abandonment and rejection, shielding himself from his mother's criticism.

As noted above, chairwork might also involve the use of more than two chairs, where each of these hosts one specific mode. Commonly, with obsessive patients the Demanding and Punitive Parental mode emerges quite often, and putting it on a specific chair, ideally also using some symbols or props might be particularly useful to the patient's disidentification process. As might happen in imagery work, the therapist or the client's Healthy Adult might talk, negotiate or eventually even banish the dysfunctional parent part. When Mark's dysfunctional parent mode emerged in therapy (and this happened quite often!) the therapist named the mode and put it on another chair, confronting it with the consequences it had had, and continued to have, for Mark's life (in Mark's case the therapist used a medal that represented this mode symbolically). This happened while the client was sitting next to the clinician, carefully observing what was going on. The therapist spoke to the parental mode, which was named "The cold flagellator", with a convinced and firm voice: "It is never enough for you! Your demands are exaggerated! With your obsession with mistakes and on rigid moral standards, you never allow Mark to rest. He must always be afraid of what might go wrong, and of how bad and evil he might be if he only had the thought of being gay! Because of you, he is always checking everything, ruminating constantly about whether he is homosexual or not, and this causes him a lot of suffering! You are taking away all his pleasure in life; all the fun, all his friends, and even 
the possibility of dating! And you do not even allow him to understand how and what he feels spontaneously! You are not good, you have to lower your requests and demands, and give Mark the chance to really understand how he feels! And if you don't allow him to do that, I will not allow you to stay here anymore!" After debriefing about what has happened and how Mark had felt while the therapist was arguing with his Demanding and Punitive mode, in the following sessions similar exercises were played with Mark's Healthy Adult (helped by the therapist), who gradually faced up to and confronted his dysfunctional parental mode.

If new modes emerge during the chairwork, such as the Vulnerable (i.e., upset, guilty, fearful of being despised) or Angry Child, or the dysfunctional coping mode, the new part is named and put on a new chair and, according to its characteristics, faced up to and confronted by the therapist and the Healthy Adult of the client. The main goal is to identify the emotions and the needs of the Vulnerable or Angry Child (see Tenore et al., 2018, this issue for more details about this mode), and to fulfill those needs in a caring and appropriate way (with a proper and adequate expression of anger). When doing so, sometimes the dysfunctional coping modes or the parental inner voices might interfere. Again, appropriate interventions to lower, negotiate or banish the unhealthy mode must be applied.

During therapy, recurrent difficult situations might arise when treating OCD patients. Some of these are listed in Table 2, with specific corresponding mode attribution and clinical intervention explained in detail.

Table 2. List of possible difficult situations that might arise during OCD treatment are reported in the first column. The corresponding dysfunctional mode and consequent experiential or relational techniques are listed, respectively in the second and third columns (adapted from Van Vreeswijk, Broersen, \& Nadort, 2012).

\begin{tabular}{|c|c|c|}
\hline Difficult Situation & Possible associated Mode & Experiential technique \\
\hline Patient refuses to do exposure & Detached or Angry Protector mode & Chairwork \\
\hline $\begin{array}{l}\text { Patient demands certainty and does not want to } \\
\text { accept any risk }\end{array}$ & $\begin{array}{l}\text { Demanding and Punitive Parent } \\
\text { mode }\end{array}$ & $\begin{array}{l}\text { Imagery work, also with the Healthy Adult, Empathic } \\
\text { confrontation or Chairwork }\end{array}$ \\
\hline Client is not in contact with his/her emotions & Detached Protector mode & Imagery work or Empathic confrontation \\
\hline Patient dissociates during exposure or in session & $\begin{array}{l}\text { Detached Protector mode or } \\
\text { Activation of Vulnerable Child }\end{array}$ & $\begin{array}{l}\text { Empathic confrontation or Chairwork for Detached } \\
\text { Protector }\end{array}$ \\
\hline $\begin{array}{l}\text { Client feels deeply disgusting and fears others' } \\
\text { rejection }\end{array}$ & Vulnerable Child & Imagery work or Empathic confrontation or Chairwork \\
\hline Client continues to act compulsions & Over-controller mode & Empathic confrontation or Chairwork \\
\hline $\begin{array}{l}\text { Patient complains that nothing changes and } \\
\text { he/she does not want to do anything more }\end{array}$ & Undisciplined Child & Empathic confrontation \\
\hline Client feels he has to do more & Demanding Parent & Chairwork \\
\hline $\begin{array}{l}\text { Patient gets angry towards his/her parents } \\
\text { because they pressure him and are demanding }\end{array}$ & Angry Child mode & Empathic confrontation and limited reparenting \\
\hline
\end{tabular}




\section{Cognitive Interventions}

In this paragraph, our intent is to present an overview of cognitive interventions in relation to guilt, specifically deontological guilt, and disgust sensitivity. As already explained in Luppino et al. (2018), these emotions play a key role in actual obsessive symptoms and in their genesis, leading towards a specific vulnerability to OC symptoms. The main cognitive technique we will focus on is acceptance, one of the most efficacious interventions for dealing with emotional distress (A-Tjak et al., 2015, for a recent review). Acceptance can be used in combination with the experiential techniques presented earlier, in order to banish the Demanding and Punitive parental modes, responsible for the intense feelings of guilt and disgust that are commonly reported by many OCD patients. Our primary attention is directed towards the strengthening of the Healthy Adult mode, in order to promote a more mindful, compassionate and accepting perspective of the self, and of life in general. Risk acceptance, the awareness that life implies taking risks and making mistakes, which are ineluctable and not necessarily related to the individual self-worth and moral value, are the key aspects that need to be addressed within therapy and which must be internalized by the Healthy Adult mode.

\section{Guilt and Disgust Acceptance}

As reported by Luppino et al. (2018), a fundamental goal of obsessive patients is to prevent or neutralize the possibility of feeling guilty within the symptomatic domain. For instance, Mark was afraid of losing his wallet; he could not tolerate the risk of being responsible for a possible gas explosion; and he could not tolerate the possibility of being gay. All these fears were associated with a profound sense of guilt and, with regard to homosexuality, with the possibility of being disgusting, and eventually despised and rejected by significant others. In addition, the possibility of being guilty was regarded as threatening, serious, likely to happen, and, more importantly, as unacceptable and unforgivable. That is to say, fear of guilt in the symptomatic domain derives from a more pervasive and grave fear of being reproachable and morally blamed. Feeling guilty would irremediably compromise one's self-worth as a moral being, which is, as noted, a valued goal for many OCD clients (Mancini, 2018).

In order to help the client reduce his/her efforts to prevent the possibility of being morally defective or regarded as repugnant and disgusting, acceptance represents a fundamental step in the treatment of OCD (Gragnani et al., 2018; Mancini, 2018). Unlike cognitive restructuring, acceptance interventions do not have the objective of reassuring the patient that the threat does not exist, or that it might be overcome. Rather, their aim is to help the client to recognize that withdrawing and neutralizing any possible risk of being guilty or loathed is impossible. As a consequence, the only pursuable way forward is to accept the possibility that threat might happen. In Table 3 we describe and compare traditional 
Table 3. Cognitive restructuring and acceptance interventions in relation to guilt and disgust-related experiences are described in detail here. The target belief is represented by a potential threat associated with the possibility of feeling guilty or being despised by others.

\begin{tabular}{ll}
\hline \multicolumn{1}{c}{ Cognitive Restructuring } & \multicolumn{1}{c}{ Acceptance intervention } \\
$\begin{array}{ll}\text { The belief that the threat (the possibility } \\
\text { of being guilty or disgusting/despised) } \\
\text { does not exist, or is unlikely to happen }\end{array}$ & $\begin{array}{l}\text { Guilt or being despised cannot be avoided; feelings of } \\
\text { guilt are in the natural order of things. } \\
\text { Trying to prevent those feelings is useless or causes } \\
\text { additional stress (criticizing and anger towards oneself, } \\
\text { sadness, and extra checking or seeking reassurance) }\end{array}$ \\
$\begin{array}{ll}\text { The client has no (or little) responsibility } \\
\text { for preventing the threat from happening }\end{array}$ & $\begin{array}{l}\text { Being morally perfect or not blameful is not a human } \\
\text { righe potential threat is minimized }\end{array}$ \\
$\begin{array}{l}\text { Feeling guilty or disgusting is unpleasant, but not } \\
\text { catastrophic: one can learn to deal with it! } \\
\text { Other relevant moral goals can be found, pursued and } \\
\text { reached. }\end{array}$ \\
\hline
\end{tabular}

cognitive restructuring with acceptance interventions. Both kinds of techniques can be used by the therapist to help the client to deal with the threat of being possibly guilty, or/and judged as disgusting or despised by others.

Acceptance means getting from a mindset of "pursuing a goal that is impossible to reach", to the point of giving it up and accepting the unrealistic nature of this goal. In the case of OCD, patients commonly think that emotions such as guilt or disgust are unacceptable feelings that one has the power to control, and the duty to prevent, at any cost. In our previous two articles we explained how both emotions, and their associated appraisals and behaviors, play a core role in the genesis of obsessive symptoms and their maintenance. Guilt acceptance implies living with the awareness of one's own moral imperfection, within a specific domain, resulting in the abandonment of behavior aimed at preventing such flaws. Mark, for example, feared being responsible and guilty for having lost his wallet, or leaving the gas valve open or the front door open. He was afraid that, if he did not do as much as he could to prevent those risks from happening, he would feel deeply wrong and evil, and would therefore be "a bad human being". On the other hand, he was also terrified by his concerns about the possibility of being gay, which would have meant being disgusting and repellent, leading towards others' scorn and rejection.

Accepting the emotion of guilt means tolerating the threat of being responsible for a future harm and accepting the risk of "being morally imperfect" within the symptomatic domain. In a similar way, OCD patients, and specifically those with washing symptoms, are helped to tolerate the possibility of being judged as disgusting by others, or being morally despised, which is associated with potential rejection. In both cases, acceptance might be addressed in several ways. A first step implies modifying the patient's belief in having the power to elude the threat (i.e., the threat of being morally guilty or disgusting). The aim is to help the patient distinguish between what is and what is not in his/her power to achieve. This might be done through the use of the Socratic dialogue and reduc- 
tio ad absurdum argument (Mosticoni, 1984; Mancini, 2018; Gragnani et al., 2018). A second step is aimed at modifying the belief that attempts to elude, or at least to reduce, the threat are valuable. This belief might be addressed focusing on the costs of solution attempts, with respect to other relevant goals, and debating the usefulness of such beliefs. Mark and his therapist identified all the cons associated with his avoidant behaviors and compulsions (that is, the detached Protector and the over-controller coping modes), such as not playing soccer, avoiding studying, social isolation, the feeling that he was ruining his life, the sense of going crazy, feeling very tired and stressed, recurrently checking the gas and the door, and so on. Further steps involve supporting the belief that feelings of guilt are in the natural order of things, and decatastrophyzing its experience. The latter can be done through Socratic dialogue, behavioral experiments, and distancing and de-fusion exercises, all the while increasing experiential acceptance. All these aspects are discussed and allow for the strengthening of the Healthy Adult mode. Additionally, these cognitive interventions can be adopted during imagery exercises and in the context of chairwork when confronting with the dysfunctional coping and parental modes.

Finally, a last phase of cognitive interventions includes helping the client to investing in reachable goals. This means fostering value awareness, identifying and defining appropriate goals in positive terms, identifying behaviors that allow goal achievement and, overall, increasing committed behavior. Mark identified making new friends, going back to the soccer, subscribing to Facebook and finishing his studies as some of his new positive goals. For each of these, specific sub-goals were identified and planned in every detail. All these exposures were completed while accepting the risk of making mistakes and of imperfection, without in any way affecting his ethical value as a human being. At the same time Mark grounded his commitment in new valuable goals related to environmental awareness, thus trying to be sustainable and more respectful towards the earth.

\section{Conclusion}

The overall aim of this trilogy was to indicate a promising theoretical integration of ST and CT elements and techniques in the treatment of OCD. There is some solid evidence that, individually, CT and ST can be useful in the understanding and treatment of OCD. However, we suggest that a combination of the two might be particularly helpful for several reasons, not least to help the patient obtain a deeper comprehension of the basis and the maintenance factors of his disorder. In fact, on the one hand the cognitive model provides us a specific, detailed and stable picture of the actual triggers, the maintenance factors and the recursive processes in the disorder, and, overall, of its internal profile. On the other hand, schemas and modes' conceptualization makes it possible to obtain a more dynamic representation of the patient's mental state in his daily life. That is to say, early maladaptive schemas allow depicting the obsessive mind, and, together with its principal goals and beliefs, consent to map their development 
over the course of the patient's life. Modes further favor a dynamic and concrete representation of the client's emotional and behavioral states. According to these premises, within the first paper by Luppino et al. (2018) we proposed how specific emotional and cognitive aspects might explain obsessive functioning. We particularly focused on the main goals and beliefs of the obsessive patient, moreover highlighting the role of deontological guilt and disgust in explaining the dynamics of the recursive processes involved in the maintenance of the disorder. All these elements together allow understanding patient's internal profile, within a CT framework (Mancini, 2018). In the second article by Tenore et al. (2018) we integrated these cognitive and emotional elements within the schema therapy context, proposing a conceptualization of the disorder in terms of schemas and modes. Early maladaptive schemas reflect the core themes reported by obsessive patients, and have their roots in early-life experiences that might represent specific vulnerability factors predisposing towards obsessive symptoms development. In both papers we also provided some clinical and research evidence about the two models, individually. Finally, in this last article, we offered a detailed overview on how the integration of ST and CT can be implemented to successfully treat OCD. We particularly concentrated on emotion-focused experiential procedures, such as imagery and chair dialogue, which might be useful to acknowledge and heal negative emotions associated with patients' stressful early life experiences. We described in detail how safe place and diagnostic imagery might be used within the first stages of the therapeutic process, heading up towards consequent imagery with rescripting and, in the final stages of therapy, Healthy Adult imagery. Further we highlighted the potential benefits associated with chairwork in understanding and reducing the dysfunctional parental and coping modes, and strengthening the Healthy Adult mode. In the last part of the paper we explained how cognitive based acceptance techniques might be used to help the patient to deal and accept negative emotional states, such as deontological guilt and disgust sensitivity, allowing a more realistic and compassionate perspective on the self.

Possible applications to other psychopathological conditions might also be hypothesized. For instance, guilt in the form of the altruistic type, intolerance of uncertainty, perfectionism and unrelenting standards might offer some examples of specific psychological features that might characterize other disorders such as depression (O'Connor et al., 2002; Gilbert, 1992), hypochondria (Fergus \& Valentiner, 2001) and eating related disorders (Shafran et al., 2002; Simpson, 2012). These core characteristics might play a role in the genesis and maintenance of specific symptoms. Getting a deeper comprehension, through the identification of their vulnerability and maintenance mechanisms, within each specific psychopathological condition, might throw new light on the functioning of the disorder and make it possible to apply appropriate clinical intervention.

\section{Conflicts of Interest}

The authors declare no conflicts of interest regarding the publication of this paper. 


\section{References}

Arntz, A. (2011). Imagery Rescripting for Personality Disorders. Cognitive Behavior and Practice, 18, 466-481. https://doi.org/10.1016/j.cbpra.2011.04.006

Arntz, A. (2012). Imagery Rescripting as a Therapeutic Technique: Review of Clinical Trials, Basic Studies, and Research Agenda. Journal of Experimental Psychopathology, 3, 189-208. https://doi.org/10.5127/jep.024211

Arntz, A., \& Weertman, A. (1999). Treatment of Childhood Memories: Theory and Practice. Behaviour Research and Therapy, 37, 715-740. https://doi.org/10.1016/S0005-7967(98)00173-9

A-Tjak, J. G., Davis, M. L., Morina, N., Powers, M. B., Smits, J. A., \& Emmelkamp, P. M. (2015). A Meta-Analysis of the Efficacy of Acceptance and Commitment Therapy for Clinically Relevant Mental and Physical Health Problems. Psychotherapy \& Psychosomatic, 84, 30-36. https://doi.org/10.1159/000365764

Basile, B., Fadda, S., De Sanctis, B., Saliani, A. M., Perdighe, C., Luppino, O. I., Tenore, K., \& Mancini, F. (2018). Early Life Experiences in OCD and Other Disorders: A Retrospective Observational Study Using Imagery with Re-Scripting Characterize OCD, But Not Other Disorders. Clinical Neuropsychiatry. [In Press]

Basile, B., Fadda, S., De Sanctis, B., Saliani, A. M., Perdighe, C., Luppino, O. I., Tenore, K., \& Mancini, F. (2018). Early Life Experiences in OCD and Other Disorders: A Retrospective Observational Study Using Imagery with Re-Scripting Characterize OCD, But Not Other Disorders. Clinical Neuropsychiatry. (In Press)

Berle, D., \& Phillips, E. S. (2006). Disgust and Obsessive-Compulsive Disorder: An Update. Psychiatry, 69, 228-238. https://doi.org/10.1521/psyc.2006.69.3.228

Brewin, C. R. (2006). Understanding Cognitive Behaviour Therapy: A Retrieval Competition Account. Behaviour Therapy and Research, 44, 765-784.

https://doi.org/10.1016/j.brat.2006.02.005

Conway, M. A., \& Pleydell-Pearce, C. W. (2000). The Construction of Autobiographical Memories in the Self-Memory System. Psychological Review, 107, 261-288.

https://doi.org/10.1037/0033-295X.107.2.261

Cooper, M. J. (2012). Working with Imagery to Modify Core Beliefs in People with Eating Disorders: A Clinical Protocol. Cognitive and Behavioral Practice, 18, 454-465.

https://doi.org/10.1016/j.cbpra.2010.08.003

Cooper, M. J., Todd, G., \& Turner, H. (2007). The Effects of Using Imagery to Modify Core Beliefs: An Experimental Pilot Study. Journal of Cognitive Psychotherapy, 21, 117-122. https://doi.org/10.1891/088983907780851577

Dibbets, P., Poort, H., \& Arntz, A. (2012). Adding Imagery Rescripting during Extinction Leads to Less ABA Renewal. Journal of Behavior Therapy and Experimental Psychiatry, 43, 614-624. https://doi.org/10.1016/j.jbtep.2011.08.006

Farrell, J. M., \& Shaw, I. A. (2018). Experiencing Schema Therapy from the Inside Out a Self-Practice/Self-Reflection Workbook for Therapists. New York/London: Guilford Press.

Fergus, T. A., \& Valentiner, D. P. (2001). Intolerance of Uncertainty Moderates the Relationship Between Catastrophic Health Appraisals and Health Anxiety. Cognitive Therapy and Research, 35, 560-565. https://doi.org/10.1007/s10608-011-9392-9

Fink, J., Pflugradt, E., Stierle, C., \& Exner, C. (2018). Changing Disgust through Imagery Rescripting and Cognitive Reappraisal in Contamination-Based Obsessive-Compulsive Disorder. Journal of Anxiety Disorders, 54, 36-48.

https://doi.org/10.1016/j.janxdis.2018.01.002 
Gilbert, P. (1992). Depression: The Evolution of Powerlessness. Hove: Lawrence Erlbaum Associates.

Gragnani, A., Buonanno, A., \& Saettoni, M. (2018) Ch. 9. Techniques of Cognitive Restructuring: Accepting Risk Cognitive Techniques. In The Obsessive Mind. Abingdon-on-Thames: Routledge. (In Press)

Kellogg, S. (2004). Dialogical Encounters: Contemporary Perspectives on "Chairwork" in Psychotherapy. Psychotherapy: Theory, Research, Practice, Training, 41, 310-320. https://doi.org/10.1037/0033-3204.41.3.310

Lee, S. W., \& Kwon, J.-H. (2013). The Efficacy of Imagery Rescripting (IR) for Social Phobia: A Randomized Controlled Trial. Journal of Behavior Therapy and Experimental Psychiatry, 44, 351-360. https://doi.org/10.1016/j.jbtep.2013.03.001

Luppino, O. I., Tenore, K., Mancini, F., \& Basile, B. (2018). An Integration of Schema and Cognitive Therapy in OCD Treatment: Goals and Beliefs of the Obsessive Mind (Part I). Psychology, 9, 2261-2277. https://doi.org/10.4236/psych.2018.99131

Mancini, A., \& Mancini, F. (2018) Rescripting Memory, Redefining the Self: A Meta-Emotional Perspective on the Hypothesized Mechanism(s) of Imagery Rescripting. Frontiers in Psychology, 20, 9-581. https://doi.org/10.3389/fpsyg.2018.00581

Mancini, F. (2018). The Obsessive Mind. Abingdon-on-Thames: Routledge.

Moreno, J. (1989). Introduction to Primary Care and Psychology. Journal of Group Psychotherapy, Psychodrama, \& Sociometry, 42, 3-12.

Moreno, Z. T. (2012). Mental Health Resources.

Morina, N., Lancee, J., \& Arntz, A. (2017). Imagery Rescripting as a Clinical Intervention for Aversive Memories: A Meta-Analysis. Journal of Behavior Therapy and Experimental Psychiatry, 55, 6-15. https://doi.org/10.1016/j.jbtep.2016.11.003

Mosticoni, R. (1984). La ricerca nevrotica dell'equilibrio. Roma: Bulzoni.

O’Connor, L. E., Berry, J. W., Weiss, J., \& Gilbert, P. (2002). Guilt, Fear, Submission, and Empathy in Depression. Journal of Affective Disorders, 71, 19-27. https://doi.org/10.1016/S0165-0327(01)00408-6

Paivio, A., Smythe, P. C., \& Yuille, J. C. (1968). Imagery versus Meaningfulness of Nouns in Paired-Associated Learning. Canadian Journal of Psychology, 22, 427-441. https://doi.org/10.1037/h0082782

Perls, F. (1973). The Gestalt Approach and Eye Witness to Therapy. Mountain View, CA: Science and Behavior Books.

Renner, F., DeRubeis, R., Arntz, A., Peeters, F., Lobbestael, J., \& Huibers, M. (2018). Exploring Mechanisms of Change in Schema Therapy for Chronic Depression. Journal of Behavior Therapy and Experimental Psychiatry, 58, 97-105. https://doi.org/10.1016/j.jbtep.2017.10.002

Roediger, E. (2012). Why Are Mindfulness and Acceptance Central Elements for Therapeutic Change in Schema Therapy Too? An Integrative Perspective. In M. van Vreeswijk, J. Broersen, \& M. Nadort (Eds.), The Wiley-Blackwell Handbook of Schema Therapy: Theory, Research, and Practice. Hoboken, NJ: Wiley-Blackwell.

Salkovskis, P. M. (1999). Understanding and Treating Obsessive-Compulsive Disorder. Behaviour Research and Therapy, 37, S29-S52.

https://doi.org/10.1016/S0005-7967(99)00049-2

Shafran, R., Cooper, Z., \& Fairburn, C. G. (2002). Clinical Perfectionism: A Cognitive-Behavioural Analysis. Behavior Research and Therapy, 40, 773-791.

https://doi.org/10.1016/S0005-7967(01)00059-6 
Simpson, S. (2012). Ch. 10. Schema Therapy for Eating Disorders: A Case Study Illustration of the Mode Approach. In The Wiley-Blackwell Handbook of Schema Therapy: Theory, Research, and Practice. Chichester: Wiley-Blackwell. https://doi.org/10.1002/9781119962830.ch10

Smucker, M. R., Dancu, C., Foa, E. B., \& Niederee, J. L. (1995). Imagery Rescripting: A New Treatment for Survivors of Childhood Sexual Abuse Suffering from Post-Traumatic Stress. Journal of Cognitive Psychotherapy, 9, 3e17.

Sprengelmeyer, R., Young, A. W., Pundt, I., Sprengelmeyer, A., Calder, A. J., Berrios, G. et al. (1997). Disgust Implicated in Obsessive-Compulsive Disorder. Proceedings of the Royal Society of London, Series B, 264, 1767-1773. https://doi.org/10.1521/psyc.2006.69.3.228

Tenore, K., Basile, B., Cosentino, T., De Sanctis, B., Fadda, S., Gragnani, A., Luppino, O. I., Perdighe, C., Romano, G., Saliani, A. M., \& Mancini, F. (2018). Efficacy of Imagery with Rescripting in Treating OCD: A Single Case Series Experimental Design (Preliminary Results). In Sixth EABCT SIG Meeting on OCD.

Tenore, K., Basile, B., Mancini, F., \& Luppino, O. I. (2018). An Integration of Schema and Cognitive Therapy in OCD Treatment: A Proposal for Theoretical Conceptualization and Rationale (Part II). Psychology, 9, 2278-2295.

https://doi.org/10.4236/psych.2018.99129

Van Vreeswijk, M., Broersen, J., \& Nadort, M. (2012). The Wiley-Blackwell Handbook of Schema Therapy: Theory, Research, and Practice. Chichester: Wiley-Blackwell. https://doi.org/10.1002/9781119962830

Veale, D., Page, N., Woodward, E., \& Salkovskis, P. (2012). Imagery Rescripting for Obsessive Compulsive Disorder: A Single Case Experimental Design in 12 Cases. Journal of Behavior Therapy and Experimental Psychiatry, 49, 1-7.

Wild, J., Hackmann, A., \& Clark, D. M. (2007). When the Present Visits the Past: Updating Traumatic Memories in Social Phobia. Journal of Behavior Therapy and Experimental Psychiatry, 38, 386-401. https://doi.org/10.1016/j.jbtep.2007.07.003

Wild, J., Hackmann, A., \& Clark, D. M. (2008). Rescripting Early Memories Linked to Negative Images in Social Phobia: A Pilot Study. Behavior Therapy, 39, 47-56. https://doi.org/10.1016/j.beth.2007.04.003

Young, J. E., Klosko, J. S., \& Weishaar, M. (2003). Schema Therapy: A Practitioner's Guide. New York: Guilford Publications. 